\title{
The impact of IT adoption in SMEs supply chains: A case of Gauteng and Free State provinces of South Africa
}

\author{
K. Mathu* and M.T. Tlare \\ Gordon Institute of Business Science (GIBS), University of Pretoria, P O Box 787602, Sandton, 2146, South Africa
}

*To whom all correspondence should be addressed

MathuK@gibs.co.za

\begin{abstract}
This study probed the influence of information technology adoption by small and medium enterprises (SMEs) in Gauteng and Free State Provinces of South Africa. The supply chain integration and collaboration of the SMEs was also explored to ascertain the IT influence. A quantitative methodology was used as it was the best way to measure the extent of the information technology (IT) influence. The participants were sent questionnaires via the e-mail and provided feedback to the researcher via the same medium. The sample size of 300 comprised the owner/manager in the manufacturing and service sector SMEs from the two provinces. The data collected was analysed using a Confirmatory Factor Analysis (CFA) method and Structural Equation Modelling (SEM) using AMOS 22 Statistical Analysis software. The findings from the study indicated that information technology adoption enhanced integration and collaboration of SMEs supply chain. It also emerged that there was wide application of information technology amongst most of the SMEs approached. The other benefits that emerged from the increased use of IT in the supply chain included enhancement of customer service, inventory management, lead time, and relationship building. Indeed, Instilling IT skills to the SMEs employees was actually knowledge enhancement in performing business tasks.
\end{abstract}

\section{Introduction}

The South African small and medium enterprises (SMEs) were a mixture of businesses that existed before the country's transition to democracy in 1994 and those that emerged thereafter. The new comers were smaller and predominantly run by black people as owner operated enterprises. Hence, there were variations in the development of the two sets of SMEs. The more established and the older types, which were the majority had more elaborate supply chain functionalities compared to the new comers. The new comers were hitherto run conventionally due to shortage of resources and skills, and operated more as 'owner-manager' design. As a result, collaboration was weak and they had inadequate flow of information that hampered their supply chain development. This study looked at how the IT adoption within the SMEs had impacted the supply chain functions in Gauteng and Free State provinces of South Africa. The study was intended for Gauteng as the South Africa's commercial hub, but Free State was added to provide a broader industry mix.

\section{SMEs background}

The advent of internet has significantly benefitted businesses including the SMEs globally. The emergence of electronic commerce (e-commerce) that could be expressed as IT adoption had been a remarkable value-add to all businesses. According to Chan, Chong and Zhou, (2012:329), the willingness by SMEs to embrace IT as they navigated through the external forces was proof of benefit accrued. The research on e-commerce sales in United States which has a very developed online business indicated a growth of 14.6 (Zaroban, 2016).

The use of internet service broadened the business outreach within their areas of operations and globally (Kaplan, Johnson, Pearch \& George, 1997:86) while research established that the environment and organisational characteristics also influenced technology innovation that could have impacted on adoption decisions (Tsai, Lee $\& \mathrm{Wu}$ 2010:255). IT played an essential role in ensuring workforce agility by providing swiftness and flexibility, which were in addition significant to supply chain agility (White \& Mohdzain, 2005:396). The Journal of Internet Baking cited researchers from South Korea that stated that the risk of internet banking indirectly influenced adoption behavior (Lee, Lee \& Kim, 2015).

A theoretical grounding based on 'technological acceptance model' was used in the study as postulated by Chuttur, (2009:1). The model stipulated that the 'systems use was a response that could be explained or predicted by user motivation, which was directly influenced by an external stimulus consisting of the actual systems features and capabilities'. Hence, the model entailed the utilisation of the systems' benefits. A research in Dubai, UAE, on a model that enhanced technology acceptance using 'innovation diffusion theory' found that the users of mobile commerce adopted it with ease (Bhatti, 2015).

There was growing recognition of the important role that (SMEs) played in economic development. They were often 
described as 'efficient and a source of job creation, incubators for big businesses and the fuel of national economic engine' (Abor \& Quartey, 2010:218). SMEs were the largest employers in all the economies and they were known to foster inter and intra-regional co-operation and vehicle for faster socio-economic growth, and poverty alleviation in nations (Cook \& Nixson, 2000:14). A media report in South Africa in 2014 indicated that SMEs created $50 \%$ of employment opportunities, and $45 \%$ contribution to GDP (Media Release 2014). According to Statistic South Africa 2016 report, the SMEs contributed $42 \%$ towards the country's growth domestic product (GDP) in 2014 (Stats SA, 2016).

\section{What constitutes SMEs in South Africa}

The South African Reserve Bank classification of SMEs based on the number of employees: Micro businesses (less than 5); very small businesses (6-20); small businesses (2150) and medium businesses (over 200) (SA Reserve Bank, 2015).

However, there were other characteristics of SMEs that comprised of owner manager and up to four employees as in the case of 'spaza' shops (Small Business Group, 2004:4).

\section{The role of SMEs in the economy}

The SMEs sector played a major role in the South African economy in terms of employment creation and income generation. They were usually the vehicle through which the lowest income people in the society gained access to economic opportunities (Ntsika, 2002:111).

A vibrant SMEs sector was crucial driver for the economic growth in a developing country as it was the key to the transformation of the society (Entrepreneur SA, 2005:3). According to the World Bank Report, SMEs played a major role in the economies and contributed up to $45 \%$ of total employment and up to $33 \%$ of GDP in emerging economies (World Bank Report, 2015).

\section{Factors affecting SMEs in South Africa}

Over $80 \%$ of SMEs in South Africa fail soon after inception for reasons ranging from lack of basic business knowledge to lack of support (Brink \& Cant, 2003:1). Often, people have good ideas, but "they do not have a clue of how to run a business" and have no underlying appreciation of business fundamentals (Ntsika, 2002:45). A South Africa Reserve Bank report indicated that the country's computer per capita was 195 units per 1000 people. The report ranked South Africa 53 out of 61 of the global emerging markets. United States led the group with 1111 computers per 1000 people (SA Reserve Bank, 2015). With unemployment rate of $26.7 \%$ in 2016, South Africa had the potential of developing SMEs to support the economic growth (Trading Economics, 2016). All businesses required financial resources in order to start trading and to fund growth. The lack of access or availability of finance can be a constraint on business growth (Cassar, 2004:262). New SMEs can be financed from the founders' own wealth and by accessing external sources of finance, whether from informal sources such as family and friends, or from formal, market-based sources such as banks, venture capitalists, and private equity firms (Herrington, Kew \& Kew, 2009:22).

The other factors adversely affecting the SMEs were state factors that included policies on the contractual and informational framework, macro-economic environment, social factors (crime, corruption and ethics) technology and the regulatory environment, bankers and industry-related problems (Olawale \& Garwe, 2010:732).

Indeed, investing in IT was crucial for business development in all firms as technology helped in formulating multidimensional strategy and maximising business opportunities (Olawale \& Garwe, 2010:731).

\section{Acceptance and adoption of e-commerce by SMEs}

A number of SMEs were forced to engage in electronic business when their dominant clients adopted electronic commerce in their businesses as in electronic purchasing system. A common occurrence in South Africa was in in state procurement process whereby the SMEs suppliers had to be registered in the state electronic data base (e-Tender Portal, 2015). A study conducted on SMEs in Indonesia indicated that developing countries were forced to adopt e-commerce in order to survive in the current global economic downturn (Rahayu, 2015).

\section{Problem statement}

The problem statement was to establish the impact of the adoption of information technology (IT) by the SMEs supply chains management from Gauteng and Free State provinces of South Africa. The two provinces were selected to broaden the industry mix for the study.

\section{The purpose of the study}

The purpose of the study was to establish the impact of the supply chain management of the SMEs in Gauteng and Free State provinces after adoption of information technology (IT).

\section{The empirical objectives of the study}

There were three empirical objectives of the study:

- To evaluate the influence of IT adoption in supply chain integration;

- To examine the impacts of supply chain integration; and

- To evaluate the impacts of IT adoption in supply chain collaboration.

\section{Hypotheses}

The study had to prove three hypotheses based on the empirical objectives. They were: 
H1. There was a positive relationship between IT
adoption and supply chain integration.

H2. Supply chain integration had a positive influence on supply chain collaboration.

H3. There was a positive relationship between IT adoption and supply chain collaboration.

Hence, a conception model was developed as follows:

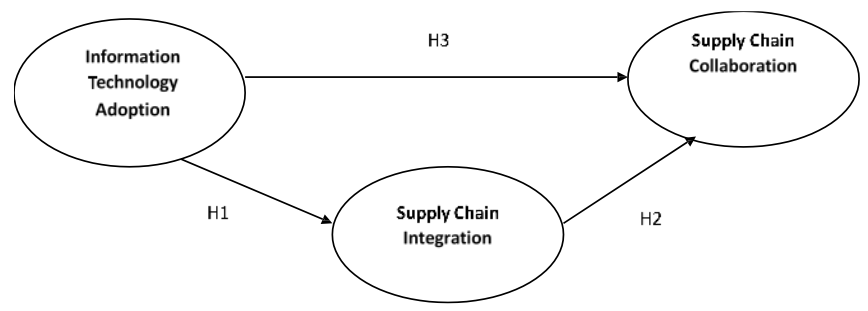

Figure 1: A conceptual research model

Source: Author's design

The model identified three variables upon which the three hypotheses were formulated:

- Predictor variable: The information technology (IT) adoption

- Moderator variable: The supply chain integration

- Outcome variable: The supply chain collaboration

The Technology Acceptance model was used to explain the relationship between the three variables and the 'Innovation Diffusion Theory' was used to elaborate the relationship between $\mathrm{th} \mathrm{e} \mathrm{m}$. The collected data was used to measure the constructs from SMEs from diverse industries from the two selected provinces. The SMEs were either owner-managed, or run by appointed managers from manufacturing and service sectors. The study aimed to establish if there was a linear relationship between information technology adoption and supply chain integration, information technology adoption and supply chain collaboration. The other aim was to determine whether or not supply chain integration had a linear relationship with supply chain collaboration.

\section{Hypotheses Development}

\section{Information Technology Adoption and Supply Chain Integration $(\mathrm{HI})$}

During the early days of information technology adoption, researchers enthusiastically expressed the rate at which the adoption was embraced by the supply chains and the transformation manifestation in the exchange-related activities (Palmer \& Griffith, 1998:38). IT adoption had vast potential to facilitate integration, and coordination among supply chain partners through the sharing of information on demand forecasts, and production schedules that dictated supply chain activities (Karoway,
1997:32). However, as in birth, adoption reflected the history of IT emergence into prominent role in businesses.

The primary activities of SMEs could be divided into a sequence of activities: out- bound logistics, marketing and sales, and service, along with support activities. Those activities were internal and external to the SMEs and their primary goal was to create value for the end-customer (Handfield \& Nichols, 1999:45). Moreover, Daughery, Stank and Keller, (2001:29) stated that the goal was proficiency through integration of activities between interrelated SMEs, and should result in reduced costs due to the exclusion of operational duplication and resources wastage. In order to realise that reduction, it required engaging in integration that was both internal and external to the SMEs.

Successful integration required the smooth flow of accurate and timely information across the supply chain partners. A case of supply chain integration strategy in food industry in Malaysia demonstrated the ease of capital flow in the industry (Saleh \& Roslin, 2015). Hence, IT adoption served as a key enabler of supply chain integration (SCI) through the capture, organisation, and sharing of vital information regarding key business processes, both within and outside SMEs boundaries (Sanders \& Premus, 2002:54). The technology acceptance (IT) to firm's mission also improved the theoretical base of adoption (Awa, Ojiabo \& Emecheta, 2015:76-94).

\section{Supply Chain Integration and Supply Chain Collaboration (H2)}

The Supply Chain Council definition of supply chain integration was "when supply chain partners interact at all levels to maximise mutual benefits" (APICS Dictionary 2013). Therefore, supply chain integration involved overseeing a system of collaboration where explicitly defined processes, responsibilities, and structures of entities are aligned with specific operational activities and the overall objectives of the supply chain integration.

Simchi-Levis, Kaminsky and Simchi-levi, (2003:5) pointed out that Supply chain integration was complex and had dynamic structures which posed challenges for developing effective collaboration. For instance, value was added to raw materials at a number of stages and through various activities before becoming the item or final product purchased by the end customer.

Supply chain collaboration is the interrelationship between the supply chain partners for enhancement of the supply chain functions (Mangan, Lalwani, Butcher \& Javadpour, 2012:49).

Technology Adoption and Supply Chain Collaboration (H3)

Information Technology played a fundamental role in developing workforce agility by providing speed and flexibility, which were also critical to supply chain agility (White \& Mohdzain, 2005:369). An agile supply chain 
involved close linkage among supply chain partners in key processes, improving procurement, forecasting, supply chain management, and new product development. IT enabled agility by allowing supply chain partners who exchanged planning and operational data, ranging from information on annual contracts, and progress reports to real-time delivery, and invoicing data (Chen \& Tsou, 2007:237).

Fawceet and Mangan, (2002:75) identified three levels of IT usage: 'firstly, to increase the quality and speed of information exchanged among channel members. Secondly, the development of core building blocks as linked information sharing, integrative inter-organisational processes, aligned goals, consistent measures, and shared risks and rewards. Thirdly, the consideration of supply chain management as a culture and philosophy'.

\section{Theoretical grounding}

With growing technological needs in the 1970's, and increasing failure of systems adoption in organisations, predicting systems use became an area of interest for many researchers. Davis, (1989:25) suggested that user's motivation could be explained by three factors: 'Perceived ease of use, perceived usefulness, and attitude towards using the system'. He hypothesised that the attitude of a user toward a system was a major determinant of whether the user would actually use or reject the system. The attitude of the user, in turn, was considered to be influenced by two major beliefs: 'perceived usefulness and perceived ease of use'.

While addressing the nursing professionals (Kaminski, 2011) expressed the diffusion of information as the process that occurred as people adopted new ideas, product, practice, philosophy and so on.

\section{Research methodology}

The study adopted a quantitative methodology and data was collected by interviewing various SMEs from the two South African provinces of Gauteng and Free State. The research design focused on the comparative historical aspects, exploratory and interpretative approach from both inductive and deductive perspectives.

A research methodology was a methodical process for solving a specific predicament. It was a discipline of learning how a research project had to be carried out. Basically, it comprised the processes by which researchers go about their work of explaining, predicting, and describing selected phenomena (Kim, 2009:328). Neill, (2007:4) stated that research methodology was defined as the study of methods by which knowledge was acquired. Hence, it provided work plan for the proposed research.

Quantitative research methods were the various schemes, algorithms and procedures used in this kind of research. They were basically value-neutral, planned and numerical. They included experimental studies, theoretical procedures, statistical approaches and numerical schemes. Research methods in general helped with the collection of data, sampling, and finding a solution to a predicament (Nahid, 2003:597).

\section{Sampling}

The sample size for quantitative research was crucial as larger samples provided more elaborate statistical findings (Lee \& Ling, 2008:302). The sample size for this study was 300 respondents.

\section{Sampling method and technique}

Probability sampling was used as it demonstrated the representativeness of the sample, and explicit statement as to how much variation was introduced, and identification of possible biases (Kumar, Aaker \& Day, 2002:306). The SMEs owners/managers in the Free State and Gauteng Provinces were sampled, using simple random sampling where each population element had an equal chance of being selected. The sampling technique was easy to-use, and it minimised the selection bias which enhanced the reliability of results.

\section{Data analysis, procedure, and statistical approach}

The data was coded and analysed from questionnaires using the Microsoft excel spread sheet. Descriptive statistics with SPSS, CFA, and path modelling were conducted with AMOS, and subsequently by the Structural equation model (SEM). SEM demonstrated, and tested the theoretical linkages of a proposed study, and the significance of the relationships between the models' constructs (Hair, Rabin, Anderson \& Tathan, 2010:20). SEM stipulated a technique where separate relationships were allowed for each set of dependent variables that provided an estimation technique for a series of separate multi-regression equations which were estimated simultaneously. By assessing each relationship simultaneously rather than separately, an incorporation of all the multi-scale items can be used to account for measurement errors within each scale (Hair et al., 2010: 20).

\section{Reliability and validity}

Reliability referred to the degree to which a measurement was consistent and stable in measuring what it was intended to measure, while validity referred to the degree to which the measurement item actually measured what it claimed to measure (Nahid, 2003:597). Reliability testing was done using Cronbach's Alpha value and composite reliability value, while validity testing involved checking both convergent and discriminant validity. Convergent validity was checked using item total correlation, item loading and AVE values. The discriminant validity was assessed using AVE values, compared to shared variance and the interconstruct correlation matrix. 


\section{Ethical considerations}

The ethical issues were paramount in research as they related to the participants, researchers and sponsoring organisations (Kumar, 2005:216).

In this research all the ethical formalities were satisfied between the researcher, and the firms where the research questionnaires were sent. A consent letter sent to those firms stated that the respondents' participation was voluntary and anonymous, and the confidentiality of the information was to be maintained. A permission letter to conduct research was eventually received from those firms.

\section{Results}

The result of this study was presented in three sections: the empirical findings as stated in the study objectives, the three hypotheses and the demonstration of reliability of the variables.

\section{The empirical findings}

The three empirical objectives were expressed and tables used for elaboration. They were:

a) to evaluate the influence of IT adoption on supply chain integration;

b) to examine the impact of supply chain integration; and

c) to evaluate the impact that IT adoption plays in supply chain collaboration.
Table 1: Response from the questionnaires

\begin{tabular}{l|c|c}
\hline Sample & Total & Percentage (\%) \\
\hline Final sample & 289 & $95.70 \%$ \\
\hline Non-responses & 8 & $2.64 \%$ \\
\hline Unavailable & 4 & $1.32 \%$ \\
\hline Discarded & 1 & $0.33 \%$ \\
\hline Original sample & 302 & $100.00 \%$ \\
\hline
\end{tabular}

Source: Author's design

The table indicates a total of 302 questionnaires were sent out and there were 289 positive responses which provided a successful rate of $95.70 \%$. This was a justifiable number to conclude an accurate report.

\section{The extent to which information technology adoption can improve supply chain integration}

The following table illustrates the extent to which information technology adoption could improve supply chain integration.

Table 2: The extent to which information technology adoption can improve - supply chain integration

\begin{tabular}{|c|c|c|c|c|c|}
\hline & $\begin{array}{c}\text { Strongly Disagree } \\
\text { n }(\%)\end{array}$ & $\begin{array}{c}\text { Disagree } \\
\text { n }(\%)\end{array}$ & $\begin{array}{l}\text { Moderately } \\
\text { Agree n (\%) }\end{array}$ & $\begin{array}{l}\text { Agree } \\
\text { n }(\%)\end{array}$ & $\begin{array}{c}\text { Strongly Agree } \\
\text { n (\%) }\end{array}$ \\
\hline Product/Service quality & $\begin{array}{l}10 \\
(3.5 \%)\end{array}$ & $\begin{array}{l}15 \\
(5.2 \%) \\
\end{array}$ & $\begin{array}{l}16 \\
(5.5 \%)\end{array}$ & $\begin{array}{c}98 \\
(33.9 \%)\end{array}$ & $\begin{array}{l}150 \\
(51.9 \%)\end{array}$ \\
\hline $\begin{array}{l}\text { Direct linkage to key } \\
\text { suppliers }\end{array}$ & $\begin{array}{l}14 \\
(4.8 \%)\end{array}$ & \begin{tabular}{c|}
9 \\
$(3.1 \%)$ \\
\end{tabular} & $\begin{array}{l}14 \\
(4.8 \%)\end{array}$ & $\begin{array}{c}86 \\
(29.8 \%) \\
\end{array}$ & $\begin{array}{l}166 \\
(57.4 \%)\end{array}$ \\
\hline Logistics integration & $\begin{array}{l}10 \\
(3.5 \%)\end{array}$ & $\begin{array}{ll}16 \\
(5.5 \%) \\
\end{array}$ & $\begin{array}{c}9 \\
(3.1 \%) \\
\end{array}$ & $\begin{array}{l}127 \\
(43.9 \%)\end{array}$ & $\begin{array}{l}127 \\
(43.9 \%)\end{array}$ \\
\hline Lower production cost & $\begin{array}{l}14 \\
(4.8 \%)\end{array}$ & \begin{tabular}{|l|}
8 \\
$(2.8 \%)$ \\
\end{tabular} & $\begin{array}{l}15 \\
(5.2 \%)\end{array}$ & $\begin{array}{l}130 \\
(45.2 \%)\end{array}$ & $\begin{array}{l}122 \\
(42.2 \%)\end{array}$ \\
\hline Trade relevant information & $\begin{array}{l}12 \\
(4.2 \%)\end{array}$ & \begin{tabular}{c|}
8 \\
$(2.8 \%)$ \\
\end{tabular} & $\begin{array}{l}14 \\
(4.8 \%)\end{array}$ & $\begin{array}{l}117 \\
(40.5 \%)\end{array}$ & $\begin{array}{l}138 \\
(47.8 \%)\end{array}$ \\
\hline Integration across the supply chain & $\begin{array}{l}10 \\
(3.5 \%)\end{array}$ & $\begin{array}{l}14 \\
(4.8 \%) \\
\end{array}$ & $\begin{array}{l}12 \\
(4.2 \%) \\
\end{array}$ & $\begin{array}{l}104 \\
(36.0 \%)\end{array}$ & $\begin{array}{l}149 \\
(51.6 \%) \\
\end{array}$ \\
\hline
\end{tabular}

Source: Author's design

The above table describes the following:

\section{Product/service quality}

The results indicated a majority $85.8 \% \quad(n=248)$ of the respondents agreed that supply chain integration played a critical role in improving the quality of products/services that SMEs provided. Only $8.7 \% \quad(n=25)$ of the respondents disagreed with this notion. About $5.5 \% \quad(n=16)$ were undecided and could not say whether it improved product/service quality or not. It can be concluded that product/service quality of SMEs owners and managers could be enhanced through supply chain integration.

\section{Direct linkage to key suppliers}

The table indicates that $87.2 \%(n=252)$ of the respondents agreed that supply chain integration improved their direct link to key suppliers. Only $7.9 \%(n=23)$ of the respondents were not of the view that this type of linkage could improve supply chain integration. Only $4.8 \% \quad(n=14)$ were undecided and could not agree or disagree with the notion. It can thus be concluded that direct linkage to key suppliers of SMEs 
owners and managers could be attributed to supply chain integration.

\section{Logistics integration}

The indication in the table was that $43.9 \%(n=127)$ of the respondents agreed that supply chain integration could help to improve logistics integration of SMEs owners and managers. An additional $43.9 \%(n=127)$ indicated that they strongly agreed that logistic integration of SMEs could be improved through supply chain integration. Only $9.0 \%$ $(n=26)$ of the respondents disagreed.

\section{Lower production cost}

The table illustrates that $87.2 \%(n=252)$ of the respondent agreed with the notion that supply chain integration could help reduce production costs in SMEs. Only 7.6\% $(n=22)$ of the respondents disagreed with the statement and the remaining $5.2 \%(n=15)$ did not agree or disagree with that notion. Therefore, it was concluded that supply chain integration reduced production costs.

\section{Trade relevant information}

The table indicate that $88.5 \%(n=255)$ of the respondents agreed that supply chain integration was very important in improving trade-relevant information of supply chain partners on SMEs. Only $7.0 \% \quad(n=20)$ of the respondents disagreed with the notion and the remaining respondents did not choose to agree or disagree. Thus, it was accepted that supply chain integration had a positive influence on trade relevance information in SMEs.

\section{Integration across the supply chain}

The ability to integrate across the supply chain was assessed as indicated in Table 2 above. The table indicates that $87.6 \%$ $(n=253)$ of the respondents agreed that supply chain integration could help improve the integration across the supply chain of SMEs. Only $8.3 \%(n=24)$ of the respondents disagreed with the statement and the remaining $4.2 \%(n=12)$ did not agree or disagree. It was concluded that supply chain integration could enhance integration across the supply chain.

\section{Accuracy analysis statistics using Cronbach's coefficient}

Accuracy analysis was established using Cronbach's coefficient and item-total correlation as indicated in the following table.

Table 3: Accuracy analysis statistics: Cronbach's coefficient and item-total correlations

\begin{tabular}{|c|c|c|c|c|c|c|c|}
\hline Research construct & \multicolumn{2}{|c|}{ Factor loading } & $\alpha$ value & Research construct & \multicolumn{2}{|c|}{ Factor loading } & $\alpha$ value \\
\hline \multirow{8}{*}{ Information Technology Adoption } & ITA1 & .643 & \multirow{8}{*}{0.94} & \multirow{8}{*}{$\begin{array}{l}\text { Supply Chain } \\
\text { Integration }\end{array}$} & SCI & .621 & \multirow{8}{*}{0.95} \\
\hline & ITA2 & .538 & & & SCI2 & .681 & \\
\hline & ITA3 & .669 & & & SCI3 & .671 & \\
\hline & ITA4 & .667 & & & SCI4 & .676 & \\
\hline & ITA5 & .606 & & & SCI5 & .612 & \\
\hline & ITA6 & .605 & & & SCI6 & .632 & \\
\hline & ITA7 & .412 & & & & & \\
\hline & ITA8 & .440 & & & & & \\
\hline & SCC1 & .413 & & & & & \\
\hline & SCC2 & .432 & & & & & \\
\hline Supply Chain Collaboration & SCC3 & .606 & 0.95 & & & & \\
\hline & SCC4 & .602 & & & & & \\
\hline & SCC5 & .597 & & & & & \\
\hline
\end{tabular}

ITA: Information Technology Adoption

SCC: Supply Chain Collaboration

SCI: Supply Chain Integration

Source: Author's design

The above table illustrates reliability statistics on information technology adoption, supply chain integration, and supply chain collaboration. The indication was that the Cronbach's alpha was 0.94. All the three variables namely the information technology adoption, supply chain integration, and supply chain collaborations were factored below 0.95 . That meant the variable was reliable as the Cronbach's alpha was above the recommended threshold of 0.7 .

\section{The three hypotheses}

The study targeted SMEs in Gauteng and Free State Provinces as they provided a balanced mix of industries comprising old and the new comers. The purpose was to establish the influence (impacts) of information technology adoption in their supply chains. 


\section{Hypothesis (H1) - Outcome}

The impact of information technology adoption on supply chain integration

The first hypothesis (H1) stated that "information technology adoption has an influence on supply chain integration of SMEs in Gauteng and Free State Provinces". There were a number of factors that led firms to adopt information technology. Those factors were attributed to innovations opened by technology, and overcoming complexities encountered in business. The evidence provided in Part (A) above indicated that successful adoption of IT by the SMEs enhanced the supply chain integration.

\section{Hypothesis (H2) - Outcome}

The influence of supply chain integration on supply chain collaboration

The second hypothesis (H2) states that "supply chain integration has an influence on supply chain collaboration on SMEs" This hypothesis investigated the influence of supply chain integration on supply chain collaboration. The empirical finding of this study found a negative linear relationship between supply chain integration and supply chain collaboration as the factor loading was $(-0.15)$. That was below the p-value of (less than the threshold of 0.5 ) as confirmed by other previous researches done on supply chain integration and supply chain collaboration. The reason for the negative linear relationship was $d u e t o$ the supply chain collaborative approach that was entirely a different paradigm to that involved in 'flow line' SMEs in Gauteng and Free State Provinces.
Therefore, it was concluded that there was a negative relationship between supply chain integration and supply chain collaboration by SMEs.

Hypothesis (H3) - Outcome

The influence of information technology adoption on supply chain collaboration

The final hypothesis (H3) claimed that "information technology adoption has an influence on supply chain collaboration" This hypothesis was derived from an objective that sought to determine whether or not information technology adoption had influence on SMEs supply chain. Therefore, a positive linear relationship was posited between information technology adoption, and supply chain collaboration. A positive linear relationship between these two constructs was established from a positive factor loading of 0.577 , (a p-value of less than c significant $* * *$ of $<0.001)$. This meant that the information technology adoption by SMEs made their supply chain collaboration with key suppliers, and customers more important as it helped increase production, decrease delivery time, and increase their sales growth.

\section{Convergent validity}

- The reliability and validity of the variables is demonstrated in the table that follows.

Table 4: Accuracy analysis statistics: Factor loadings

\begin{tabular}{|c|c|c|c|}
\hline Research construct & Factor loadings & Research construct & Factor loading \\
\hline \multirow{8}{*}{ Information Technology Adoption } & .524 & \multirow{8}{*}{ Supply Chain Integration } & .760 \\
\hline & .467 & & .633 \\
\hline & .682 & & .630 \\
\hline & .643 & & .663 \\
\hline & .669 & & .763 \\
\hline & .712 & & .710 \\
\hline & .568 & & \\
\hline & .660 & & \\
\hline \multirow{5}{*}{ Supply Chain Collaboration } & .600 & & \\
\hline & .620 & & \\
\hline & .849 & & \\
\hline & .659 & & \\
\hline & .773 & & \\
\hline
\end{tabular}

Source: Author's design

The above table illustrates the factor loading of information technology adoption, supply chain integration and supply chain collaboration. The factor loadings for information technology adoption were (ITS1-0.524, ITA3-0.682, ITA40.643, ITA5-0.669, ITA6- 712, ITA7-0.568 and ITA8-660) met the convergent validity value of threshold 0.5 excluding (ITA2-0.467) which states (the firms with supply chain partners met productivity standards in evaluation with industry/customer requirements). The factor loading for supply chain integration and supply chain collaboration met the recommended threshold of 0.5 and furthermore, this study was consistent with the study of Virakul and Lee, (2010:85) 


\section{Limitation to the study}

The limitations to this study was mainly that data was collected from the SMEs from only two provinces of South Africa, namely Gauteng and Free State and not from the whole country. The two provinces were used in order to optimise the diversity of firms for the purpose of the study. The current period of slow economic growth in South Africa required a comprehensive study that covered the whole country to establish the actual causes of economic stagnation for the purpose of addressing the problem.

The logistics of mailing the questionnaires to the respondents and subsequent follow-up for feedback was cumbersome, but ended well.

Subsequently, a one-on-one interview would have had more impact, but only a limited budget was available.

\section{Conclusion}

The study looked at the influence of information technology to the supply chain of small and medium enterprises in the two provinces of South Africa: Gauteng and Free State. A quantitative methodology was undertaken by sending questionnaires for data collection. A total of 302 questionnaires were dispatched to the earmarked firms and there was a response of 289 respondents $(95.70 \%)$. The data analysis was carried out using Confirmatory Factor Analysis (CFA) and Structural Equipment Modelling (SEM) using MOSS 22 Statistical Analysis software. The study pursued three empirical objectives, and used a conceptual model with three variables that was supported by three hypotheses. The three hypotheses were proved and one of them $\mathrm{H} 2$ came out negative, while the other two $\mathrm{H} 1$ and $\mathrm{H} 3$ were positive. Accuracy analysis statistics was conducted on the three research constructs to conclude the findings. The constructs were IT adoption, supply chain collaboration and supply chain integration. The study concluded that IT adoption by SMEs impacted positively to the supply chain by enhancing integration and collaboration as elaborated by convergent validity.

\section{Recommendations}

The study concluded that IT adoption by the SMEs enhanced their supply chain collaboration and integration. Hence, it was crucial for intensive application of IT in all businesses as was presently being addressed by the 'Big Data' and the 'internet-of-things'. The IT adoption was better described by the use of world wide web, internet and the 'digital disruption' which were revolutionising conventional business processes. The revolution aimed to render businesses lean, agile and more sustainable. That was the ideal trend to save the planet earth from diminishing resources by consuming the available resources sparingly to sustain the present and future generations.

\section{References}

Abor, J. \& Quartey, P. 2010. 'Issues in SNE development in Ghana and South Africa', Journal of Finance and Economics, 39:218-228.

APICS Dictionary. 2013. The essentials of supply chain reference. Chicago: APICS.

Awa, H. O., Ojiabo, O.U. \& Emecheta, B.C. 2015. 'Integrating TAM, TPB and TOE frameworks and expanding their characteristic constructs for e-commerce adoption by SMEs', Journal of Science and Technology Management, 6(1):76-94.

Bhatti, T. 2015. 'Exploring factors influencing the adoption of mobile commerce', Journal of Internet Banking and Commerce. [online]. URL: http://www.icommercecentral.com/openaccess/exploring-factors-influencing-the-adoption-of-mobilecommerce.php?aid=38513. pdf.

Brink, A. \& Ccant, M. 2003. 'Problems experienced by small businesses in South Africa', Small Enterprise Associations, 16(1):1-20.

Cassar, G. 2004. 'The financing of business start-ups', Journal of Business, 19(2):261-283.

Chan, F.T.S., Chong, A.Y.L. \& Zhou, L. 2012. 'An empirical investigation of factors affecting e-collaboration diffusion in SMEs', International Journal of Production Economics, 138:329-344.

Chen, J.S. \& Tsou, H.T. 20007. Information technology adoption for service innovation practices and competitive advantage: the case of financial firms. [online]. URL: https://www.information.net /ir/123/paper 314. Html.

Chuttur, M.M. 2009. 'Overview of the technology acceptance model: Origins, development and future directions', Sprouts: Working Papers on Information Systems, 9(37): 1-50.

Cook, P. \& Nixson, F. 2000. Finance and small and mediumsized enterprise development. IDPM. University of Manchester (Finance and Development Research Programme), Working paper Series No.14.

Daughery, P.J., Stank, T.P. \& Keller, S.B. 2001. 'Supply chain collaboration and logistical service performance', Journal of Business Logistics, 22(1):29-48.

Davis, F.D. 1989. 'Perceived usefulness, perceived ease of use and user acceptance of information technology', MIS Quarterly, 13(3):319-339.

Entrepreneur South Africa. 2005. An investigation into youth entrepreneurship in selected South African secondary schools: An exploratory study. [online]. URL: https://www.unisa.ac.za/ contents/facilities/service_dept/docs/SABVIEW15_3_CHAP3.pdf.

E-Tender Portal. 2015. Treasury launches central database and etender publication portal. [online]. URL: http://www.gov.za/speeches/launching-central-supplier-databaseand-etender-publication-portal-8-apr-2015-0000.pdf.

Fawceet, S.E. \& Mangan, G.M. 2002. 'Supply chain integration: rhetoric or reality?' International Journal of Physical Distribution and Logistics management, 32(1):339-61. 
Hair, J. F., Babin, B.J., Anderson, R.E. \& Tatham, R.L. 2010. Multivariate data analysis. A global perspective. 7th Edition. New Jersey: Prentice-Hall.

Handfield, R.B., \& Nichols, E.L. 1999. Introduction to Supply Chain Management. Upper Saddle River: Prentice-Hall.

Herrington, M., Kew, J. \& Kew, P. 2009. Global entrepreneurship monitor, South Africa report. [online]. URL: http://www.gbs.nct.ac.za/gbswebb/userfiles/gemsouthafrica2000pd f.

Kaminski, J. 2011. 'Diffussion of information theory: Theory in nursing informatics', Canadian Journal of Nursing Informatics, 6(2), 1444.

Kaplan, T.E., Johnson, I.W., Pearce, C.G. \& George, G. 1997. 'The strategic role of communication technology in small businesses: Where we are and where we should be going', American Business Review, 15(1):86-91.

Karoway, C. 1997. 'Superior supply chains pack plenty of byte', Purchasing Technology, 8(11):32-35.

Kim, S. 2009. 'Individual-level factors and organisational performance in government organisations', Journal of Public Administration Research and Theory, 15(2):254-261.

Kim, S.W. 2009. ' An investigation on the direct and indirect effect of supply chain integration on firm performance', International Journal of Production Economics, 199:328-346.

Kumar, S. 2005. 'Performance and impact of self-help group in Punjab - Past experience and roadmap ahead', The Microfinance Review, 2(1):19-25.

Kumar, V., Aaker, D.A. \& Day, G.S. 2002. Essentials of marketing research. 2nd Edition. New York: John Wiley.

Lee, N. \& Ling, I. 2008. Doing business research. Thousand Oaks, CA: Sage.

Lee, K.S., Lee, H.S. \& Kim, S.Y. 2015. Factors influencing the adoption behavior of mobile banking: A South Korean perspective. [Online]. URL: http://www.icommercecentral.com/openaccess/factors-influencing-the-adoption-behavior-of-mobilebanking-a-south-korean-perspective.php?aid=38487.

Mangan, J., Lalwani, C., Butcher, T. Javadpour, R. 2012. Global logistics \& supply chain management. 2nd Edition. West Essex: John Wiley.

Media Release. 2014. Small businesses, huge potential for South Africa. [online]. URL: http://www.idc.co.za/home/mediaroom/articles/738-small-business,-huge-potential-for-southafrica.html.

Nahid, G. 2003. Understanding reliability and validity in qualitative research. [online]. URL: https://www.nova.edu/ssss/ QR/QR84/golafshani.pdf.

Neil, T. 2007. Power and empowerment. [online]. URL: https://www.books.google.co.za/books/about/power_and _empowerment.html?d=sb1gPQAACAAJS/redir_esc=y.
Ntsika Enterprise Promotion Agency. 2002. State and small business development in South Africa Annual Review. [online]. URL: http://ntsika.org.za.pdf.

Olawale, F. \& Garwe, D. 2010. 'Obstacles to the growth of new SMEs in South Africa: A principal component analysis approach', African Journal of Business Management, 4(5):729-738.

Palmer, J.W. \& Griffith, D.A. 1998. 'Information intensity: a paradigm for understanding web site design', Journal of Marketing Theory and Practice, 6(3):38-42.

Rahayu, R. 2015. Determining factors of e-commerce adoption by SMEs in developing countries: Evidence from Indonesia. [online]. URL: $\quad$ http://www.sciencedirect.com/science/article/pii/ S1877042815039026. Pdf.

Saleh, Z.M. \& Roslin, R.M. 2015. 'Supply chain integration strategy: A conceptual model of supply chain relational capital enabler in the Malaysian food processing industry', Contemporary Issues in Management and Social Science Research 172: 585-590.

Sanders, N.R. \& Premus, R. 2002. 'IT applications in supply chain organisations: A link between competitive priorities and organisational benefits', Journal of Business Logistics, 23(1):65-83.

Simchi-Levi, D., Kamisky, P. \& Simchi-Levi, E. 2003. Designing and managing the supply chain concepts: strategies and case studies. New York: McGraw-Hall.

Small Business Advisory Group. 2004. Small and Medium Businesses in New Zealand: Report of the Small Business Advisory Group, August.

South African Reserve Bank. 2015. The role of small businesses in the economy. [online]. URL: https://www.resbank.co.za/ Lists/Speeches/Attachments/452/Role\%20of\%20small\%20busines s\%202015\%20.pdf.

Statistic South Africa. 2016. Small, medium and micro enterprise sector of South Africa. [online]. URL: http://www.seda.org.za/Publications/Publications/The\%20Small,\% 20Medium\%20and\%20Micro\%20Enterprise $\% 20$ Sector $\% 20$ of $\% 20$ South $\% 20$ Africa $\% 20$ Commissioned $\% 20$ by $\% 20$ Seda.pdf.

Trading Economics. 2016. South African inflation rate forecast 2016-2020. [online]. URL: https://tradingeconomics.com/southafrica/inflation-cpi/forecast.

Virakul, B. \& Lee, D. 2010. 'Human resources management, ethical context, and personnel consequences: A commentary essay', Journal of Business Research, 63(8):908-910.

White, A.E.D.M. \& Mohdzain, M. 2005. 'The role of emergent information technologies and systems in enabling supply chain agility', International Journal of Information Management, 25(5):396-410.

World Bank Report. 2015. Small and Medium Enterprises (SMEs) Finance. 01 September. [online]. URL: http://www.worldbank.org/en/topic/financialsector/brief/smesfinance.pdf.

Zaroban, S. 2016. U.S. e-commerce grows $14.6 \%$ in 2015. Ecommerce Sales. [online]. https://www.internetretailer.com/2016/02/17/us-e-commercegrows-146-2015.pdf. 